\title{
Correction to: Synthesis and characterization of CuZnO@GO nanocomposites and their enhanced antibacterial activity with visible light
}

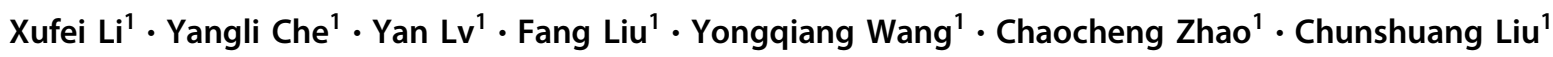

Published online: 8 December 2018

(c) Springer Science+Business Media, LLC, part of Springer Nature 2018

Correction to: Journal of Sol-Gel Science and Technology 2018

https://doi.org/10.1007/s10971-018-4872-y

The original version of this article contained a mistake in "dot multiplication" throughout the article. The mid dots implying multiplication was erroneously deleted during the production process.
For example, unit "100 $\mathrm{mg} \mathrm{L}^{-1}$ " should read as "100 $\mathrm{mg} \cdot \mathrm{L}^{-1 "}$. In section 3.2.3 titled Oxidative stress induced by $\mathrm{CuZnO} @ \mathrm{GO}$ nanocomposites, 4th line "superoxide radical $\left(\mathrm{O}_{2}^{-}\right)$" should read as "superoxide radical $\left(\bullet \mathrm{O}_{2}^{-}\right)$".

The original article has been corrected.

The original article can be found online at https://doi.org/10.1007/ s10971-018-4872-y.

Fang Liu

liufangfw@163.com

1 Department of Environmental and Safety Engineering, College of Chemical Engineering, China University of Petroleum, 266580

Qingdao, China 